Reprinted with permission from: Plant Disease. Dec. 1991. 75(12):1201-1203.

Published and copyrighted by: The American Phytopathological Society.

http://www.apsnet.org

\title{
Comparison of methods for selecting fungi pathogenic to leafy spurge
}

\author{
S. M. YANG, W. M. DOWLER, and D. R. JOHNSON \\ The authors are with the Foreign Disease-Weed Science Research Unit, Agricultural Research Service, \\ U.S. Department of Agriculture, Ft. Detrick, Bldg. 1301, Frederick, MD 21702.
}

\begin{abstract}
:
Studies were conducted to compare six inoculation methods for preliminary screening of potential fungal biocontrol agents for leafy spurge (Euphorbia esula). The six inoculation methods included 1) applying spore suspensions to surface-disinfested, detached leaves of leafy spurge in petri dishes; 2) applying spore suspensions to untreated, detached leaves of leafy spurge in petri dishes; 3) applying spore suspensions to untreated leaves on intact plants of leafy spurge; 4) placing a block of agar with mycelium (ABM) on surface-disinfested, detached leaves in petri dishes; 5) placing an ABM on untreated, detached leaves in petri dishes; and 6) placing an ABM on leaves of intact leafy spurge plants. Of 200 fungal isolates in 16 genera, 27, 16, 4, 82, 70, and 10\% induced symptoms on leafy spurge using methods 1-6, respectively. Not all pathogenic isolates were identified by methods 1-3 because the spore suspensions did not stay on the leaves readily. Methods 4 and 5 often identified the weak pathogens because the detached leaves were kept at conditions optimum for infection. Method 6 identified the highly pathogenic isolates and was dependable, easy, effective, and rapid. The upper 20 leaves on leafy spurge reacted consistently to pathogenic isolates. Method 6 is now used routinely in our laboratory for preliminary screening of pathogens of leafy spurge and has been used to select several potential biocontrol isolates for further studies.
\end{abstract}

Leafy spurge (Euphorbia esula L.) is a perennial weed of grasslands in North America. Chemical control of the weed is costly, contaminates groundwater, and is difficult (7). The use of plant pathogens for control of leafy spurge is considered a potentially effective control method. Therefore, a search for highly virulent fungal pathogens for use as potential biocontrol agents for leafy spurge was initiated. Many fungi have been previously isolated from diseased leafy spurge plants collected in China and the United States 
(Montana, Nebraska, and North Dakota). Potential biocontrol agents have then been selected from among these isolates. The conventional method for selecting pathogenic fungi is to apply spore suspensions to seedlings and incubate the inoculated seedlings in a dew chamber or high humidity chamber for 48 hours (3). Because this method is timeconsuming and not always reliable and because different target weeds require different methods for detecting pathogens, we decided that a rapid, more dependable method of evaluation was needed. The objective of our study was to compare six inoculation methods to determine which one could best be used routinely for preliminary identification of virulent pathogens.

\section{Materials and methods}

Inoculum. Numerous fungi were previously isolated from leafy spurge. Two hundred isolates were selected from among those collected in China and the United States in 1989 and 1990. Isolates were grown on Difco potato-dextrose agar (PDA) and stored at $0-5^{\circ} \mathrm{C}$ until used. For production of spores, the isolates were grown on PDA, potato-carrot agar (PCA) $(20 \mathrm{~g}$ of potato and $20 \mathrm{~g}$ of carrot boiled for 1 hour in $1 \mathrm{~L}$ of distilled water, then $20 \mathrm{~g}$ of agar added to the filtrate to make $1 \mathrm{~L}$ ), or Difco malt agar and kept at $20-25^{\circ} \mathrm{C}$ with a 12-hour photoperiod $\left(40 \mu \mathrm{E} \cdot \mathrm{s}^{-1} \cdot \mathrm{m}^{-2}\right)$ for 2-3 weeks.

Preliminary studies indicated that spores of Alternaria, Curvularia, and Myrothecium germinated better in dextrose or sucrose solution than in distilled water alone (S.M. Yang et al, unpublished). Yang (6) reported that Curvularia senegalensis (Speg.) Subramanian germinated better in $1 \%$ sucrose solution than in tap water. Spore suspensions $\left(10^{6}-10^{8}\right.$ spores per milliliter) were prepared from 2- to 3-week-old cultures by suspending the spores in sterile $2 \%$ dextrose solution amended with $0.1 \%$ polyoxyethylene sorbitan monolaurate (Tween 20) and filtered through two layers of cheesecloth throughout the tests. Agar blocks with mycelium (ABM) were cut with a No. 2 cork borer $(0.4 \mathrm{~cm}$ diameter) from the margin of colonies of 3- to 5-day-old cultures grown on PDA.

Preparation of detached leaves. Healthy leaves from the upper 10 leaves were detached from greenhouse-grown leafy spurge plants (collection 1982 MT000, seeds from Montana) and divided into two groups. Leaves in one group were placed in a solution of $5 \% \mathrm{NaOCl}$ and $100 \%$ ethanol $(20: 1, \mathrm{v} / \mathrm{v})$ for $5-10$ minutes and then washed in sterile distilled water for another 5-10 minutes. The surface-disinfested leaves were placed on sterile moistened filter paper in petri dishes (five leaves per plate). The leaves in the other group (untreated) were similarly placed on the sterile moistened filter paper in petri dishes (five leaves per plate).

Identification of fungi from diseased leafy spurge. The isolates were identified to genera according to morphology of the conidia or mycelium (Rhizoctonia) (1) produced on the aforementioned media.

\section{Methods of inoculation}

Six inoculation methods were tested including: 1$)$ a drop of spore suspension $(5 \mu 1$ containing $10^{3}-10^{5}$ spores) was placed on surface-disinfested, detached leaves on mois- 
tened filter paper in petri dishes; 2) a drop of spore suspension was placed on untreated, detached leaves on moistened filter paper in petri dishes; 3) a drop of spore suspension was placed on untreated leaves on intact plants; 4) an agar block with mycelium (ABM) was placed on surface-disinfested, detached leaves on moistened filter paper in petri dishes; 5) an ABM was placed on untreated, detached leaves on moistened filter paper in petri dishes; and 6) an ABM was placed on untreated leaves on intact plants. After inoculation, the detached leaves in petri dishes were incubated at $22 \pm 3^{\circ} \mathrm{C}$ with 12 -hour photoperiod $\left(40 \mu \mathrm{E} \cdot \mathrm{s}^{-1} \cdot \mathrm{m}^{-2}\right)$. The inoculated leaves on intact plants were incubated in a dew chamber at $20 \pm 2^{\circ} \mathrm{C}$ or $25 \pm 2{ }^{\circ} \mathrm{C}$ (Myrothecium and some isolates of Bipolaris and Fusarium) in the dark for 16-20 hours and then moved to a greenhouse. The ABM was not removed from plants after the dew period. Reactions were observed 2-7 days after inoculation. Formation of lesions, wilting and curling of leaves at the site of inoculation, or death of inoculated leaves indicated disease development. Isolates that infected at least three leaves in each of two tests (or two out of three tests in some isolates) were considered pathogenic.

Twenty-five isolates each were tested using the six inoculation methods (five leaves per treatment) each time. This test was run eight times with different isolates (200 isolates total). Leaves inoculated with a known pathogen of leafy spurge, Alternaria angustiovoidea E. Simmons (4) from Krupinsky (3) and leaves treated with sterile dextroseTween 20 solution or a block of sterile agar were included in each test to serve as controls but were not used in statistical analysis. The controls were used as an index of whether or not to accept the results of inoculation with the 25 isolates in each test. If detached leaves in petri dishes or nontreated leaves on intact plants showed lesions when treated with sterile dextrose-Tween 20 solution and sterile ABM or showed no disease symptoms when inoculated with $A$. angustiovoidea, the results of inoculation with the 25 isolates in that test were not accepted. The percentage of the controls that produced symptoms were $100 \%$ when inoculated with A. angustiovoidea and $0 \%$ when inoculated with sterile $\mathrm{ABM}$ or solution. To minimize the error mean square, the controls were not used in statistical analysis. Each experiment was repeated at least once. Duncan's new multiple range test was applied to compare the means of pathogenic isolates identified by the six inoculation methods.

Effect of leaf position on pathogenicity of five selected isolates of $\boldsymbol{A}$. alternata (Fr.:Fr.) Keissl. All leaves on young (less than 10 leaves) to flowering plants (40 or more leaves) of leafy spurge (collection 1989 NE001, root pieces from Nebraska, provided by J. R. Frank of our laboratory) were inoculated with ABM of five pathogenic isolates of $A$. alternata (isolates 41, 79, 84, 101, and 110). The inoculated plants were incubated in the dew chamber in the dark at $20 \pm 2^{\circ} \mathrm{C}$ for $16-20$ and then moved to greenhouse benches. Reactions were observed 1 week after inoculation. This test was repeated once.

Further inoculation of leafy spurge with pathogens selected by inoculation methods 4 and 6. Twenty isolates of Alternaria sp., two isolates of Bipolaris sp., 10 isolates of Fusarium sp. (not including the 18 isolates of Alternaria and Bipolaris, and Fusarium selected by inoculation method 6), one isolate each of Ascochyta sp. and Cladosporium sp., two isolates each of Curvularia sp. and Penicillium spp., three isolates each of Chaetomium sp. and Phoma sp., and five isolates of Stemphylium sp., which were selected by 
inoculation method 4 as pathogens of leafy spurge, and the 19 pathogenic isolates in four genera selected by inoculation method 6 (Table 1) were used for further inoculation studies. Spore suspensions of each isolate prepared as previously described were atomized until runoff to 10 leafy spurge plants grown in 10-cm-diameter pots (two plants per pot). After inoculation, the plants were incubated in the dew chamber in the dark at 20 or $27^{\circ} \mathrm{C}$ for 48 hours and then maintained in the greenhouse for 2 weeks. Leafy spurge plants atomized with dextrose-Tween 20 solution served as controls. The test was repeated four times.

Table 1. Number of isolates pathogenic using six inoculation methods for disease development by fungal genera pathogenic to leafy spurge.

\begin{tabular}{|c|c|c|c|c|c|c|c|}
\hline \multirow[b]{2}{*}{ Fungi $^{\mathrm{w}}$} & \multirow{2}{*}{$\begin{array}{c}\text { Isolates tested }^{\mathrm{x}} \\
\text { (no.) }\end{array}$} & \multicolumn{6}{|c|}{ Inoculation method ${ }^{\mathrm{y}}$} \\
\hline & & 1 & 2 & 3 & $\overline{4}$ & 5 & 6 \\
\hline Alternaria & 127 & $43^{z}$ & 24 & 7 & 114 & 98 & 16 \\
\hline Ascochyta & 1 & 0 & 0 & 0 & 1 & 1 & 0 \\
\hline Aspergillus & 2 & 0 & 0 & 0 & 0 & 0 & 0 \\
\hline Bipolaris & 4 & 1 & 0 & 0 & 3 & 2 & 1 \\
\hline Chaetomium & 3 & 1 & 0 & 0 & 3 & 3 & 0 \\
\hline Cladosporium & 2 & 0 & 0 & 0 & 1 & 1 & 0 \\
\hline Curvularia & 2 & 2 & 2 & 0 & 2 & 2 & 0 \\
\hline Epicoccum & 10 & 1 & 1 & 0 & 8 & 8 & 0 \\
\hline Fusarium & 22 & 4 & 3 & 0 & 20 & 17 & 1 \\
\hline Myrothecium & 1 & 1 & 1 & 1 & 1 & 1 & 1 \\
\hline Penicillium & 5 & 0 & 0 & 0 & 2 & 0 & 0 \\
\hline Pestalotia & 2 & 0 & 0 & 0 & 0 & 0 & 0 \\
\hline Phoma & 6 & 0 & 0 & 0 & 3 & 2 & 0 \\
\hline Rhizoctonia & 2 & & $\ldots$ & $\ldots$ & 0 & 0 & 0 \\
\hline Genus in Sphaeriales & 5 & 0 & 0 & 0 & 0 & 0 & 0 \\
\hline Stemphylium & 6 & 0 & 0 & 0 & 5 & 4 & 0 \\
\hline Total & 200 & 53 & 31 & 8 & 163 & 139 & 19 \\
\hline
\end{tabular}

${ }^{\mathrm{w}}$ All isolated from diseased leafy spurge.

${ }^{\mathrm{x}}$ The same 200 isolates shown in Table 2.

${ }^{\mathrm{y}} 1$ and 2, applying spore suspensions to surface-disinfested and untreated, detached leaves of leafy spurge on moistened filter paper in petri dishes; 3, applying spore suspensions to untreated leaves on intact plants of leafy spurge; 4 and 5, placing a block of agar with mycelium (ABM) on surface-disinfested and untreated, detached leaves on moistened filter paper in petri dishes; and 6, applying ABM to untreated leaves on intact leafy spurge plants.

${ }^{\mathrm{z}}$ Isolates that infected at least three leaves in each test were counted as pathogenic.

Reisolation of the fungi from the infected leaves on intact plants. Tissue pieces $(0.3 \mathrm{X} 0.8 \mathrm{~cm})$ were cut from the infected leaves, surface-disinfested as previously described, and placed on PDA plates (four tissue samples per plate) and incubated at 20$25^{\circ} \mathrm{C}$ with a 12 -hour photoperiod $\left(40 \mu \mathrm{E} \cdot \mathrm{s}^{-1} \cdot \mathrm{m}^{-2}\right)$ for $4-5$ days. Mycelium from each colony was transferred to new PDA or PCA plates amended with penicillin $(30 \mathrm{mg} / \mathrm{L})$ and streptomycin $(100 \mathrm{mg} / \mathrm{L})$ for fungal identification. 


\section{Results and discussion}

Identification of the fungi. Sixteen genera of fungi were identified from among the 200 isolates used in this study (Table 1). Seven, five, two, 12, 11, and four genera of fungi produced symptoms on leafy spurge by inoculation methods 1-6, respectively. The four genera of fungi induced symptoms by method 6 are A. alternata, Bipolaris sp., Fusarium sp., and Myrothecium verrucaria (Albertini and Schwein.) Ditmar:Fr.

Methods of inoculation. When spore suspensions were applied to disinfested, detached leaves (method 1), 53 of the 198 isolates (27\%) (two isolates of Rhizoctonia were not counted) induced symptoms (Table 2). When the same spore suspensions were applied to untreated, detached leaves (method 2), 31 isolates (16\%) induced symptoms. However, only eight isolates (4\%) induced symptoms when the same spore suspensions were applied to leaves on intact plants (method 3). When ABM was applied to disinfested, detached leaves (method 4), untreated, detached leaves (method 5), and the leaves on intact plants (method 6), $163(82 \%), 139$ (70\%), and $19(10 \%)$ of the 200 isolates, respectively, induced symptoms. Lesions or wilting occurred on leaves overnight after inoculation by ABM with highly pathogenic isolates but required 3-7 days after inoculation with spore suspensions. When ABM of A. angustiovoidea from Krupinsky was applied to leaves of leafy spurge, the pathogen infected all inoculated leaves in each test. However, when spore suspensions of the same pathogen were applied to leaves of leafy spurge, the pathogen inconsistently infected leaves. This may have been because the spores did not adhere easily to the leaves and the spores on leaves of intact plants required a long period of dew after inoculation to cause infection (7). Leaves treated with dextrose-Tween solution or a block of agar did not have lesions.

The number of isolates that induced symptoms by methods 4 and 5 was not statistically significant but was significantly different from all other methods tested (Table 2).

Effect of leaf position on leafy spurge on pathogenicity of five selected isolates of A. alternata. The upper 20 leaves from the top were consistently infected and killed by the pathogenic isolates, but leaves between 21 and 40 from the top were inconsistently infected and the degree of severity was also inconsistent. The susceptibility to A. alternata of leaves on intact plants lower than 40 was also inconsistent. The upper stems, especially at the tip, were consistently killed by the pathogenic isolates. The inoculated flowers also were killed by the pathogens. However, when ABM was applied to leaves and stems of young plants (not flowering), the severity of infection was not affected by the position of leaves; all leaves were killed. The five selected pathogenic isolates behaved similarly. Therefore, we recommend using young plants or leaves from the upper part of the old plant for preliminary screening of fungal isolates as potential biocontrol agents for leafy spurge. 
Table 2. Percentage of pathogenic isolates that produced symptoms on leafy spurge when inoculated by six methods in eight experiments

\begin{tabular}{ccccccc}
\hline & \multicolumn{5}{c}{ Inoculation method $^{\mathrm{y}}$} \\
\cline { 2 - 7 } Experiment $^{\mathrm{x}}$ & 1 & 2 & 3 & 4 & 5 & 6 \\
\hline 1 & 12 & 4 & 0 & 76 & 68 & 4 \\
2 & 28 & 12 & 4 & 92 & 84 & 8 \\
3 & 16 & 16 & 0 & 92 & 92 & 4 \\
4 & 17 & 4 & 0 & 92 & 84 & 8 \\
5 & 25 & 17 & 4 & 72 & 68 & 16 \\
6 & 12 & 8 & 8 & 84 & 48 & 12 \\
7 & 44 & 40 & 8 & 68 & 60 & 12 \\
8 & 60 & 24 & 8 & 76 & 52 & 12 \\
Mean $^{\mathrm{z}}$ & $27 \mathrm{~b}$ & $16 \mathrm{~b}$ & $4 \mathrm{c}$ & $82 \mathrm{a}$ & $70 \mathrm{a}$ & $10 \mathrm{c}$ \\
\hline
\end{tabular}

${ }^{\mathrm{x}}$ Each experiment had 25 isolates.

${ }^{\mathrm{y}} 1$ and 2, applying spore suspensions to surface-disinfested and untreated, detached leaves of leafy spurge on moistened filter paper in petri dishes; 3 , applying spore suspensions to untreated leaves on intact plants of leafy spurge; 4 and 5, placing a block of agar with mycelium (ABM) on surface-disinfested and untreated, detached leaves on moistened filter paper in petri dishes; and 6, applying ABM to untreated leaves on intact leafy spurge plants.

${ }^{\mathrm{z}}$ Numbers followed by the same letter in the mean row are not significantly different according to Duncan's new multiple range test $(P=0.05)$.

Further inoculation of leafy spurge with the pathogens selected by inoculation methods 4 and 6. None of the isolates of Alternaria sp., Ascochyta sp., Bipolaris sp., Chaetomium sp., Cladosporium sp., Curvularia sp., Epicoccum sp., Fusarium spp., Penicillium spp., Phoma spp., or Stemphylium sp. that produced symptoms by inoculation method 4 but not by method 6 infected plants in the greenhouse when spore suspensions were atomized on leafy spurge. This indicates that method 4 was inappropriate to be used for screening pathogenic fungi for leafy spurge. Three of the 16 pathogenic isolates of $A$. alternata and one isolate each of Fusarium sp. and $M$. verrucaria selected by inoculation method 6 consistently produced severe symptoms on greenhouse-grown leafy spurge. However, spore suspensions of Bipolaris inconsistently infected leafy spurge but consistently infected corn (Zea mays L.). One isolate of A. alternata from Nebraska severely damaged the flower of leafy spurge in field trials in Nebraska when spores suspended in invert emulsion were applied to the field-grown leafy spurge (2).

For preliminary screening of pathogenic fungi for leafy spurge, the application of spore suspensions to leaves (methods 1-3) has the following disadvantages: 1) it is not reliable because spore suspensions may not stay on the leaf surface, even with use of a wetting agent, 2) some fungi cannot be tested because they did not produce spores easily, 3 ) it is time-consuming and more media are required because each colony from original isolation plates needs to be separately transferred to new culture media for production of spores, 4) spores of some fungi required a long period of dew after inoculation to cause infection, and 5) it required about 3-4 weeks to determine pathogenicity.

Application of ABM to detached leaves (methods 4 and 5) favored symptom development by weakly pathogenic isolates because the detached leaves were maintained in an optimum temperature and relative humidity for infection. Inoculation method 6 eliminated many weak pathogens (Alternaria and Fusarium species). 
Application of ABM to the nondetached leaves has the following advantages: 1) it is rapid, the pathogenic isolate can be identified in less than 7 days from the initiation of isolation, 2) it is dependable and effective because only highly virulent isolates are selected, and 3) it is time- and space-saving because only the highly pathogenic isolates will be used for further studies. We consider the application of ABM to nondetached leaves to be an easy and suitable technique for primary screening of fungi as potential biocontrol agents for control of leafy spurge and similar target weeds. We have adopted this method for use in our laboratory for preliminary screening of fungi. Screening tests have resulted in the selection of several isolates of Alternaria and one isolate each of Fusarium and Myrothecium species for further studies.

Reisolation of the fungi from the infected leaves on intact plants. The 19 isolates selected by method 6 and the five isolates of $A$. alternata were reisolated from 70 to $90 \%$ of tissue pieces cut from the lesions of infected leaves. These results confirm infection of leafy spurge by A. alternata, Fusarium, and Myrothecium species.

A. alternata has been reported to be a pathogen of spotted knapweed (Centaurea maculosa Lam.) (5). However, this is the fast report of A. alternata as a pathogen of leafy spurge. This is also the first report of Fusarium sp. and M. verrucaria as pathogens of leafy spurge.

\section{Literature cited}

1. Barnett, H. L., and Hunter, B. B. 1972. Illustrated Genera of Imperfect Fungi. 3rd ed. Burgess Publishing Co., Minneapolis, MN. 241 pp.

2. Frank, J. R., Yang, S. M., Johnson, D. R., and Dowler, W. M. 1991. The interaction of Alternaria sp., invert emulsion, and glyphosate on leafy spurge (Euphorbia esula L.) control. Abstr. Weed Sci. Soc. Am. 31:44.

3. Krupinsky, J.M., and Lorenz, R.J. 1983. An Alternaria sp. on leafy spurge (Euphorbia esula). Weed Sci. 31:86-88

4. Simmons, E.G. 1986. Alternaria themes and variations (14-16). Mycotaxon 25:195-202.

5. Stierle, A., Cardellina, J., II, Park, S. H., and Strobel, G. 1989. Maculosin, a host specific toxin from Alternaria alternata on spotted knapweed. Am. Chem. Soc. Nat. Meet. Agrochem. Div. Abstr. 105.

6. Yang, S.M. 1973. Isolation and effect of temperature on spore germination, radial growth, and pathogenicity of Curvularia senegalensis. Phytopathology 63:1541-1542.

7. Yang, S.M., Johnson, D.R., and Dowler, W.M. 1990. Pathogenicity of Alternaria angustiovoidea on leafy spurge. Plant Dis. 74:601-604. 